\title{
EFFECT OF RESIDUAL NON-CONDENSABLE GASES ON THE PERFORMANCE OF A CARBON DIOXIDE EVAPORATOR AND THE SYSTEM PERFORMANCE
}

\author{
Jing $\mathrm{Hu}^{\mathrm{a}, *}$, Mingxing $\mathrm{Du}^{\mathrm{b}}$ \\ ${ }^{a}$ School of Energy and Safety Engineering, Tianjin Chengjian University, Tianjin 300384, China \\ ${ }^{b}$ Tianjin Key Laboratory of Control Theory \& Applications in Complicated System, Tianjin University of Technology, Tianjin 300384, China
}

\begin{abstract}
Inert gases are conveniently used for leak detection. Relative to $\mathrm{CO}_{2}$, majority of the inert gases are non-condensable. It is of great significance to understand the effects of residual non-condensable gases on the performance of a refrigeration system. This paper investigates, both theoretically and experimentally, on the impact of residual non-condensable gases on the performance of a carbon dioxide $\left(\mathrm{CO}_{2}\right)$ evaporator and the system performance. A theoretical analysis indicates that residual non-condensable gases can convert homogeneous nucleation into a heterogeneous nucleation process and accelerate phase change, thus, reducing superheat or incipient boiling temperature. To investigate the influence of residual non-condensable gases on the performance of an evaporator and the $\mathrm{CO}_{2}$ trans-critical refrigeration cycle system, experiments adding a small amount of $\mathrm{N}_{2}$ and $\mathrm{Ar}$ into the system are carried out. Residual non-condensable gases have different effects on the parameters of refrigerant properties and nucleate boiling under different operating conditions. Experimental results indicate that at a lower inlet temperature within 1\%, 2\%, 3\% of residual gases concentration, the heat transfer coefficient of evaporator and refrigeration coefficient of the system increase with the addition of $\mathrm{N}_{2}$ or Ar, but decrease at higher temperature with addition of the residual gas, or at a concentration of $4 \%$.
\end{abstract}

Keywords: Residual gas; carbon dioxide; refrigeration system; evaporator; cooling capacity

\section{INTRODUCTION}

In air conditioners and refrigerators, the restricted use of conventional refrigerants, such as hydrofluorocarbons (HFCs), chlorofluorocarbons (CFCs), and hydrochlorofluorocarbons (HCFCs), allows for the protection of the environment against the potentially elevating global warming and the depleting ozone layer characteristics (Mastrowski et al., 2019; Andersen et al., 2018; Abasa et al., 2018). Using natural refrigerants, such as carbon dioxide $\left(\mathrm{CO}_{2}\right)$, which is non-toxic, nonflammable, low-cost, and environment-friendly, may be practically preferable as these do not contain unknown environmental hazards. $\mathrm{CO}_{2}$ has been considered as a promising alternative refrigerant because aside from the advantages already cited, it is also ozone friendly, has negligible global warming potential, and has excellent thermophysical properties (Lorentzen et al., 1993; Karampour et al., 2018; Hazarika et al., 2018; Ju et al., 2018). Nevertheless, the critical temperature is $31.1^{\circ} \mathrm{C}$, which leads to that the heat dissipation process is usually above the critical point, but the evaporation process occurs in the subcritical region. Hence, it is conventionally called transcritical cycle for basic $\mathrm{CO}_{2}$ refrigeration system. In addition, the operation pressure is commonly ranging from 8$12 \mathrm{MPa}$, and the pressure difference between the high and low pressure sides is extremely high, resulting in a large throttling loss (Dai et al., 2018; Cao et al., 2019). Considerable throttle losses in its trans-critical cycles lead to lower system efficiency compared to conventional subcritical refrigerant cycles. Considering that climate change is not only influenced by refrigerant leakages but also by energy consumed during the lifetime of refrigerating equipment, an increase in energy consumption can likely offset its environmental advantage (Wang et al.,
2018; Yu et al., 2018; Nawaz et al., 2018; Wang et al., 2019). Thus, an essential option to lower the environmental impact is to improve the energy efficiency of the system and reduce energy consume during system operation.

Generally, for service or daily maintenance of the $\mathrm{CO}_{2}$ trans-critical refrigeration cycle, an inert gas is used for leak detection. Relative to $\mathrm{CO}_{2}$, common inert gases, such as $\mathrm{N}_{2}$ and $\mathrm{Ar}$, are non-condensable gases. A highly effective vacuum for complete removal of a residual gas may lead to a greatly increased cost. However non-thorough vacuuming may allow a small amount of non-condensable gases to remain and get mixed with the $\mathrm{CO}_{2}$ working medium. Non-condensable gases may remain in the system, which influences the performance of the system. It is of great significance to understand the effects of residual non-condensable gases on the performance of a refrigeration system.

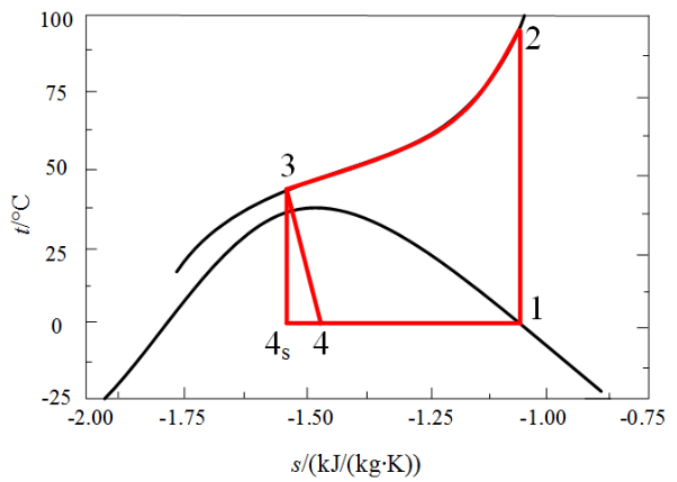

Fig. 1 T-s diagram of carbon dioxide trans-critical cycle 
Fig.1 shows the T-s diagram of carbon dioxide trans-critical cycle. The vapor is compressed to be high pressure and high temperature gas in compressor which is the process from point 1 to point 2 . The heat rejection process occurs in the supercritical region in gas cooler which is the process from point 2 to point 3 . In order to decrease the throttle loss, sometimes an expander is employed to replaces the throttle valve. The isentropic expansion process in expander is the process from point 3 to point 4 s. While the real expansion process in throttle valve is the process from point 3 to point 4 . After expansion process, the fluid flows into the evaporator to absorb heat. The evaporation process is in the subcritical region which is the process from point 4 (or 4 s) to point 1 .

There are a few researches on the effect of a non-condensable gas on the performance of expander in $\mathrm{CO}_{2}$ trans-critical cycle. Tian et al. (2011) confirmed that non-condensable gas could accelerate the phase change and improve the expander performance by experimental research on the $\mathrm{CO}_{2}$ trans-critical heat pump. $\mathrm{Li}$ (2013) assessed the performance of the expander in a $\mathrm{CO}_{2}$ trans-critical cycle when the $\mathrm{N}_{2}$ concentration increased from $1 \%$ to $4 \%$. The experimental results showed that the recovery work of the expander with the presence of an additive is higher than that without additive.

The evaporator is one of utmost importance among the components influencing the cycle efficiency. But, very limited number of studies have been conducted on the effect of non-condensable gas on evaporation process in a $\mathrm{CO}_{2}$ trans-critical cycle. The presence of a small number of non-condensable gas can also accelerate the phase change in the evaporator, which is similar to improve the performance of the expander. At this point, the heat rejection process of supercritical fluid in the cooler in the trans-critical cycle of $\mathrm{CO}_{2}$ is significantly different from the condensation in the condenser in a conventional vapor-compression cycle. In a conventional vapor-compression refrigeration system, a small amount of non-condensable gases can significantly reduce the vapor condensation heat transfer in the condenser because the non-condensable gases accumulates at the liquid and vapor interface, forming a noncondensable gas layer, which significantly slows the mass transfer between the vapor and the liquid film (Wu et al., 2018). The noncondensable gases can significantly degrade the performance of the condenser, and decrease the system performance. However, during the heat rejection process in the trans-critical cycle of $\mathrm{CO}_{2}$, because this is not a condensation process, non-condensable gases do not have much effect on the heat transfer performance of the cooler. It is possible to improve the performance of the refrigerating system. This article primarily reports the effect of a non-condensable gas on the performance of the evaporator in the transcritical carbon dioxide cycle and the impact to the systemic performance.

From the perspective of evaporator, the heat transfer performance and boiling hysteresis are influenced by surface topography, surface wettability, fluid properties, wall superheat, and heat flux (Yuan et al., 2018; Pradhan et al., 2019; Hong et al., 2019; Lu et al., 2007). A theoretical research and analysis show that the presence of a noncondensable gas, as well as contact angle, can result in heterogeneous nucleation and exert large influence on the incipient point of vapor bubbles and the phase change process. Corty and Foust (1955) and Bankoff et al. (1958) suggested that the widely accepted trapped-vapor theory, stating that cavities on heating surfaces can trap vapors and, then, act as nuclei, is the most likely theory for explaining the origin of a boiling bubble. Experimental results show that heat transfer enhancements by such cavities are obtained with an improvement of heat transfer coefficient by eightfold times (Kandlikar et al., 2013; Wang et al., 2019). Yuan developed a model of heterogeneous bubble nucleation on a heated surface from an insoluble gas bubble. It is found that the energy barrier and the critical radius of bubble formation are small at large initial insoluble gas bubble (Yuan et al., 2016). Bubble dynamics and thermodynamic theories were also applied in predicting the onset of nucleate boiling and the embryo's critical radius, agreeing with that of the experimental results (Thiagarajan et al., 2015; Mu et al., 2017).
Besides, nanobubbles could attain a stable shape with a contact angle larger than 90 degrees in supersaturated liquid, whose heated surfaces can serve as nucleation sites. In addition, local surface hydrophobicity induces heterogeneous nucleation at a reduced superheat, as the nanobubbles on the hydrophobic sites become activated and form a nucleus seed (Tyrrell et al., 2001; Yang et al., 2007). Qi and Klausner (2006) hypothesized the occurrence of nanobubbles for heterogeneous nucleation, whereas $\mathrm{Nam}$ and $\mathrm{Ju}$ (2008) analyzed the incipience of nanobubbles at low superheat. This study initially provides evidence for heterogeneous nucleation caused by residual non-condensable gases, and, then, determines the effect of the presence of such gases on the performance of the $\mathrm{CO}_{2}$ evaporator and the $\mathrm{CO}_{2}$ trans-critical refrigeration cycle system.

\section{THEORETICAL ANALYSIS}

In this paper, $\mathrm{N}_{2}$ and Ar were selected as the residual non-condensable gases. Table 1 describes the properties of $\mathrm{CO}_{2}, \mathrm{~N}_{2}$ and $\mathrm{Ar}$. In terms of the refrigerant distribution among the system equipment, the residual gas mixed with the refrigerant was found in overall system.

Table 1 Properties of pure working medium.

\begin{tabular}{|c|c|c|c|}
\hline Working medium & $\mathrm{CO}_{2}$ & $\mathrm{~N}_{2}$ & $\mathrm{Ar}$ \\
\hline Molecular Weight & 44.01 & 28.01 & 39.95 \\
\hline Critical Temperature (K) & 304.13 & 126.19 & 150.69 \\
\hline Critical Pressure (MPa) & 7.377 & 3.396 & 4.863 \\
\hline Saturation Temperature (K), $2 \mathrm{MPa}$ & 253.65 & 115.60 & 129.74 \\
\hline Saturation Temperature (K), 2.5 MPa & 267.60 & 123.62 & 138.71 \\
\hline
\end{tabular}

In the phase change process in the evaporator, the superheat phenomenon exists, which leads to a phase change delay. It is noted that homogeneous nucleation within the liquid bulk requires very high levels of superheat. Here it is necessary for the newly formed gas phase to tear apart the liquid, and hence overcome its enormous cohesiver strength. At low levels of the residual non-condensable gases, however, gas bubbles will nucleate within the liquid at pre-existing metastable gas cavities, in the vessel surface in contact with the liquid, on suspended particles, or from metastable micro-bubbles in the liquid bulk. Accelerating phase change of refrigerant by increasing gas nucleus can improve the evaporator performance. For impure liquids, nucleation could be promoted due to factors such as bubbles, steam bubbles, impurities, and rough surfaces, belonging to heterogeneous nucleation, that is, they reduce nucleation barrier and increase nucleation rate. The presence of a small amount of residual non-condensable gases hardly affects the physical properties of the refrigerant, but the liquid-to-gas phase change was more intense.

Based on the observation that superheat is much lower than that of homogeneous nucleation, a heterogeneous nucleation is alternately believed to originate from vapor/gas trapping cavities (Mu et al., 2017). Cavitation is characterized mainly by the appearance of cavitation bubbles, which can be steam bubbles or gas bubbles containing undissolved gas. However, during formation, they usually exist in an unstable form. If the bubbles are too large, they will float to the surface due to buoyancy. Nevertheless, if they are too small, the gas will be completely dissolved, and the steam will be completely condensed due an increase in surface tension. Certain parasitic substrates are required for the stable appearance of undissolved gas or uncondensed steam in a liquid. Solid surface are typically characterized by microscopic cavities and crevices. They can be used as a parasitic matrix where micro-bubbles or bubbles are attached to the solid. Furthermore, a non-condensing gas easily produces gas core at the hole, in which heat gain gradually grows up to produce bubbles.

Based on reviews and analyses, a primary cavitation number will increase with an increase in gas content due to the presence of noncondensable gases (Knapp et al., 1970). Before nucleation, a sphericalcap shaped embryo, which consists of insoluble gas and vapor, sits on a 
crevice solid surface in the superheated fluid. The schematic diagram is shown in Fig.2. Liquid evaporates into the embryo during the process of nucleation, followed by the formation of a vapor-gas bubble.

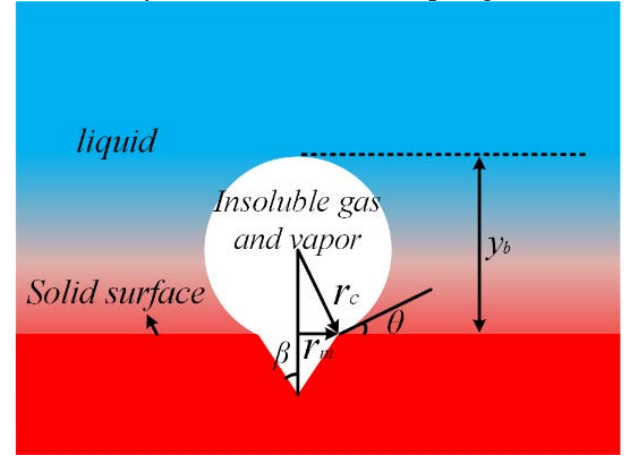

Fig. 2 Bubble nucleation point

As shown in Fig.2, a spherical-cap shaped embryo which consists of insoluble gas and vapor sits on a solid surface in the superheated fluid. Liquid evaporates into the embryo during the process of nucleation and then vapor-gas bubble is formed. A linear temperature distribution exists in the thermal boundary layer of the liquid adjacent to the wall. We will discuss the bubble nucleation temperature and its initial size based on the classical kinetics of nucleation. Hsu et al. (1962) proposed that the onset of nucleation occurs when the temperature at tip of the bubble is great than or equal to the saturation temperature corresponding to the pressure inside the bubble, i.e,

$T_{l}\left(y_{b}\right) \geq T_{b}$

where $y_{b}$ and $T_{b}$ can be determined from the Yong-Laplace and ClausiusClaperon equations.

$$
\frac{d T}{d \rho}=\frac{T}{h_{f g} \rho_{v}}
$$

For heterogeneous nucleation in superheat liquids, the following formula of bubble nucleation density can be used (Li et al., 2004).

$$
\begin{aligned}
& J_{\text {het }}=N_{0}^{2 / 3} \psi\left(\frac{k T_{n l}}{h_{f g}}\right) \exp \left[-\frac{16 \pi \sigma^{3} \omega}{3 k T_{n l}\left(P_{b}-P_{l}\right)^{2}}\right] \\
& \psi=\frac{1}{2}(1+\cos \theta) \\
& \omega=\frac{1}{4}(1+\cos \theta)^{2}(2-\cos \theta)
\end{aligned}
$$

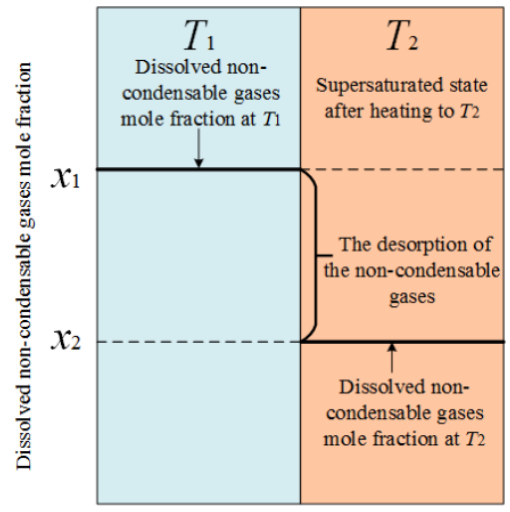

Fig. 3 Dissolved non-condensable gases mole fraction at $T_{1}$ and $T_{2}$

A minute pocket of non-condensable gases usually trapped in the crevices with evaporator surface submerged in subcritical $\mathrm{CO}_{2}$ results in a preexisting gas-liquid interfacial area that can act as an embryo for bubble growth. Supersaturation may be achieved by raising the temperature of the wall surface, as shown in Fig. 3. The saturation mole fraction is equal to $x_{1}$ at temperature $T_{1}$. When the temperature goes from $T_{1}$ to $T_{2}$, the saturation mole fraction reduces to $x_{2}$. The desorption of non- condensable gases from solution causes bubble nucleus. Consequently, unlike homogenous boiling where very large liquid superheats are necessary for initiation of the phase change process, heterogeneous boiling bubble nucleation needs only a relatively small wall superheat. Furthermore, in heterogeneous nucleation, the incipient temperature can be computed from the classical nucleation kinetics.

Dissolved non-condensable gases are present in liquid levels depending on their temperature, solubility, and exposure history. Due to the very low concentration, the amount or solubility of a gas in a fluid can be determined using thermodynamic and ideal gas laws. Whereas temperature in the evaporator is above any of the mixture components' critical temperature, an expression using Henry's law is valid. In principle, Henry's law expresses the equilibrium amount of a dissolved gas in a liquid at a given temperature as

$P_{g b}=H \times C_{g}$

where $C_{g}$ varies as a function of temperature.

At temperature $T_{1}$ and $T_{2}$, the difference in the non-condensable gases equilibrium pressure for the two states is

$\Delta P=P_{1}-P_{2}=H\left(x_{1}-x_{2}\right)=P_{2}\left(\frac{x_{1}}{x_{2}}-1\right)$

In a gas cavity, the bubble nucleus for heterogeneous nucleation on a surface due to the pressure difference. The radius of curvature of the critical bubble nucleus $r_{c}$ can be determined from Eq.(8).

$r_{c}=\frac{2 \sigma}{P_{b}-P_{l}}$

The pressure in the vapor bubble is consists of two parts:

$P_{b}=P_{v b}+P_{g b}$

If the isothermal compressibility of liquid is neglected, $\mathrm{Li}$ et al. (2004) gave the formulas for $P_{v b \text {, }}$

$P_{v b}=P_{s}\left(T_{n l}\right) \exp \left(-C_{g}\right)$

Equilibrium theory provides the superheat equation for the bubble nucleus, where $T_{s}$ is saturated temperature. Due to the evaporator absorbs heat, bubbles generate from trapped microcavities with the temperature increases. According to the Hsu's theory, nucleation temperature with the effect of the dissolved gas taken into consideration can be expressed as

$T_{n l}-T_{s}=\frac{T_{s} \exp \left(C_{g}\right)}{h_{f g} \rho_{v}}\left(\frac{2 \sigma}{r}-H C_{g}\right)$

Fig. 4 displays the calculated values of $T_{n l}$. Note that with an increase in $\mathrm{N}_{2}$ concentration, the nucleation temperature and superheat or energy required for the existence of bubble decreased. Therefore, according to the analysis above, the non-condensable gas can convert homogeneous nucleation into a heterogenic nucleation process to reduce the evaporator superheat.

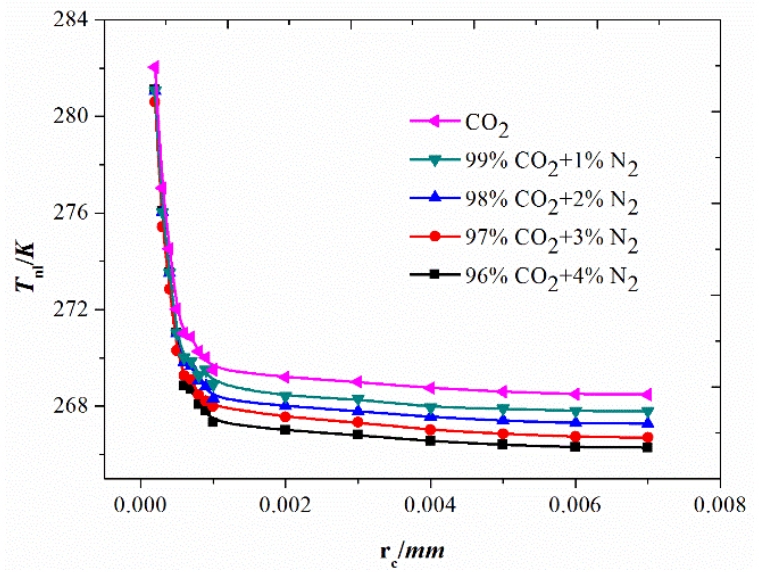

Fig. 4 Influence of $\mathrm{N}_{2}$ concentration on nucleation temperature 


\section{EXPERIMENTAL APPARATUS AND PROCEDURES}

\subsection{Experimental apparatus}

Experiments performed herein were aimed at evaluating the influence of $\mathrm{N}_{2}$ and $\mathrm{Ar}$ on the nucleate boiling heat transfer and system refrigeration performance. Fig. 5 illustrates a schematic diagram of the experimental setup. The experimental system consists of the $\mathrm{CO}_{2}$ trans-critical cycle, and chilling and cooling water systems. The $\mathrm{CO}_{2}$ trans-critical cycle includes several components as follows. A reciprocating compressor has a displacement of $3.5 \mathrm{~m}^{3} / \mathrm{h}$ and a rated input power of $4 \mathrm{~kW}$. A gas cooler that allow carbon dioxide to flow inside the tube is self-designed. The expander is installed in parallel to the throttle valve.

A double-tube type evaporator is test section, which also is selfdesigned. The inner tubes of the evaporator (shown in the magnified sections of evaporator in Fig. 5) are composed of three copper pipes with the inner and outer diameter of $1 \mathrm{~mm}$ and $3 \mathrm{~mm}$, respectively, which are twisted into a spiral. The outer tube of the evaporator is copper pipe with the external diameter of $28 \mathrm{~mm}$. To reduce heat losses, the pipes are covered by thermal insulators. The entire design minimized heat loss and resulted in a uniformly distributed heat flux along the copper tube circumference.

T-type thermocouples to measure the temperature of the inter wall of one of inner tubes are attached at 8 locations along the test section. At each point, the temperature at four circumferential locations was measured and the average values are used in calculating the heat transfer coefficient. The water temperature change in the test tube is measured by thermocouples inserted into the ends of the evaporator. The inlet and outlet pressure in the test section were measured with a precision pressure transmitter.

The $\mathrm{CO}_{2}$ sample had $99.9 \%$ purity. The non-condensable gases concentration were controlled by measuring the charging weights of $\mathrm{CO}_{2}$, $\mathrm{N}_{2}$, and $\mathrm{Ar}$, which were measured with a precision balance at $\pm 0.01 \mathrm{~g}$ accuracy.

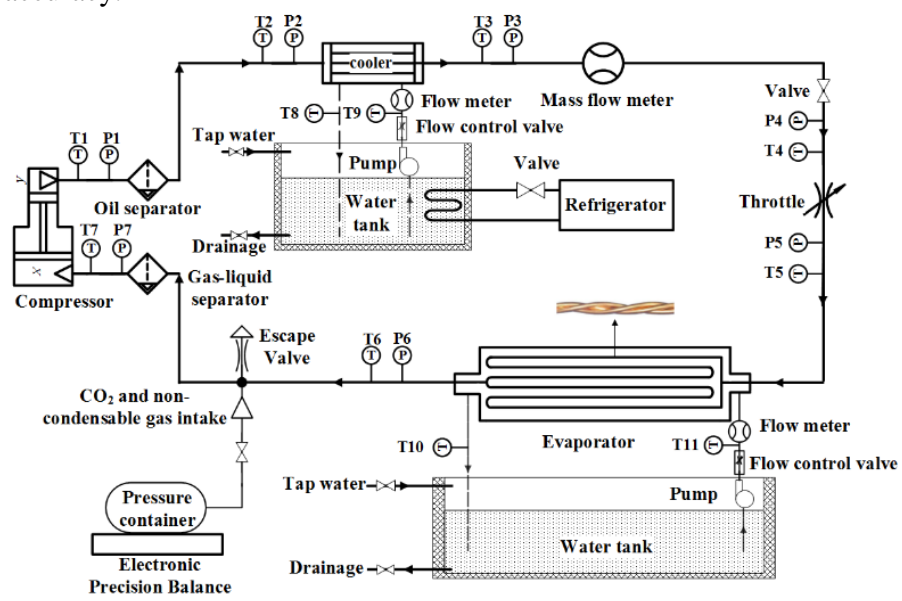

Fig. 5 Schematic of a carbon dioxide trans-critical cycle system

\subsection{Experimental procedure}

Experimental data were collected based on the following protocol. First, $\mathrm{CO}_{2}$ charge was recorded and the system was ensured to operate stably without residual gas. The inlet temperature of the evaporator was allowed to reach different evaporating temperatures with adjustment of the throttle valve at various openings. Second, $\mathrm{N}_{2}$ or Ar was assigned with certain mass and added into the system respectively. In this way, the concentration of non-condensable gases was controlled by measurement of the charging weight of both $\mathrm{CO}_{2}$ and the non-condensable gases. Third, the experiment was conducted under the condition that the noncondensable gas had mass ratios of $1 \%, 2 \%, 3 \%$, and $4 \%$, respectively. The data were collected during the stable operation of the system.

\subsection{Data Reduction}

The heat flow rate is obtained from the energy balance on the water side: $Q=m_{\text {wat }} \cdot C_{\text {wat }}\left(T_{\text {wat }, \text { in }}-T_{\text {wat }, \text { out }}\right)$

The average heat transfer coefficient is obtained from the following equation:

$$
\begin{aligned}
& k=\frac{Q}{A \Delta t_{m}} \\
& \Delta t_{m}=\frac{\left(T_{\text {wat }, \text { in }}-T_{\text {wat }, \text { out }}\right)}{T_{\text {wat }, \text { in }}-T_{s}} \\
& \ln \frac{T_{\text {wat }, \text { out }}-T_{s}}{}
\end{aligned}
$$

The system's coefficient of performance (COP) is defined as the ratio of the evaporator's cooling capacity $Q$ and the power input to the compressor $W$.

$$
C O P=\frac{Q}{W}
$$

\section{RESULTS AND DISCUSSION}

The durability and stability of the system with the blends can be examined indirectly by some operational parameters, such as the compressor discharge pressure, the compressor discharge temperature, pressure ratio and compressor power consumption. One of the important operational parameters of the compressor is discharge temperature, which has an obvious effect on the stability of the blends and lubricant as well as the lifetime of the compressor. The experimental result shows that the compressor discharge temperature decreases with the increase of concentration of $\mathrm{N}_{2}$ and Ar. The system is stable and reliable. The compressor discharge pressure and power consumption increases with the increase of concentration of $\mathrm{N}_{2}$ and Ar. At $-4^{\circ} \mathrm{C}$ of evaporating temperature, discharge pressure increases to up to $11.61 \%$ when the concentration of $\mathrm{N}_{2}$ is $4 \%$. The compressor pressure ratio decreases slightly with the increase of concentration of $\mathrm{N}_{2}$ and $\mathrm{Ar}$.

The experimental results show that the operating pressure increases when there is $\mathrm{N}_{2}$ or $\mathrm{Ar}$ in the system. Fig. 6 and 7 display the variation of pressure drop of the evaporator with the evaporator's inlet temperature. The pressure drop increased with the inlet temperature increases. At the same inlet temperature, the pressure drop of the pure $\mathrm{CO}_{2}$ is minimal, and the addition of non-condensable gas increases the pressure drop, which tends to increase with the increase of concentration. In addition, the experimental results show the power of compressor and the pressure drop in the gas cooler increase with the presence of non-condensable gas.

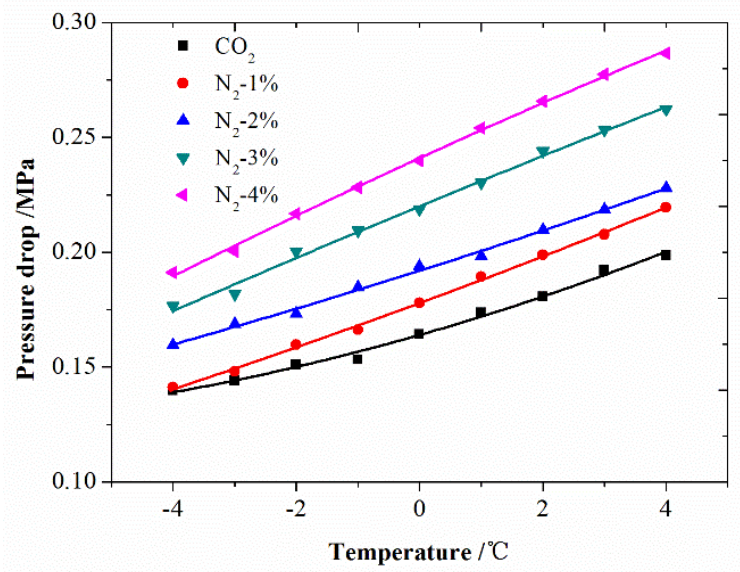

Fig. 6 Effect of $\mathrm{N}_{2}$ on the pressure drop of a $\mathrm{CO}_{2}$ evaporator 


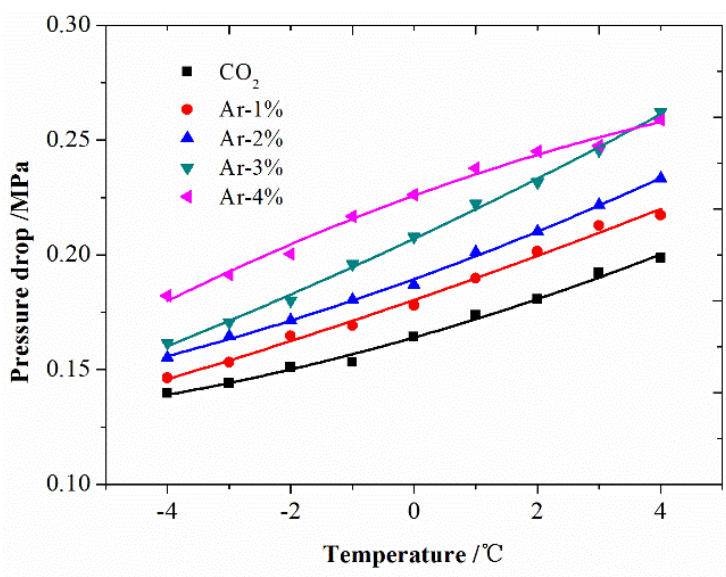

Fig. 7 Effect of Ar on the pressure drop of $\mathrm{CO}_{2}$ evaporator

Fig.8 describe the influence of the evaporator's inlet temperature on the heat transfer coefficient at various $\mathrm{N}_{2}$ concentrations, which were both maximized at the optimum inlet temperature. Fig.8 indicates when the inlet temperature is lower than about $2^{\circ} \mathrm{C}$, the heat transfer coefficient is higher with the concentration of $\mathrm{N}_{2}$ ranging from $1 \%$ to $3 \%$. At $-1^{\circ} \mathrm{C}$, $k$ increases by $5.32 \%, 7.90 \%$ and $10.09 \%$ when the concentration of $\mathrm{N}_{2}$ is $1 \%, 2 \%$ and $3 \%$, respectively. Owing to the lower the temperature, the higher surface tension, which in turn increased the cavitation threshold. At this point, $\mathrm{N}_{2}$ easily produces gas core at the hole, which can reduce nucleation barrier and enhance the heat transfer, and the higher concentration of $\mathrm{N}_{2}$, the higher the heat transfer coefficient. On the other hand, the experimental results show that the heat transfer coefficient could be reduced at higher temperature $\left(>2^{\circ} \mathrm{C}\right)$ by adding $\mathrm{N}_{2}$. The reason is that as the temperature increases, the surface tension decreases and the nuclear boiling process is very easy to occur. Meanwhile, $\mathrm{N}_{2}$ speed ups the stirring of the swirling boundary layer to improve dryout of $\mathrm{CO}_{2}$. When increasing $\mathrm{N}_{2}$ concentration to $4 \%$, lower heat transfer coefficients are measured. This is due to the greater change of thermophysical properties at higher $\mathrm{N}_{2}$ concentration, in which saturation pressure increase sharply, and the liquid film may be entrained more easily into the vapour core and the dryout inception can be encountered at lower quality.

Fig.9 shows the variation of the COP regarding $\mathrm{N}_{2}$ concentration. The COP increased at inlet temperature lower than $1^{\circ} \mathrm{C}$ within $1 \%, 2 \%$, and $3 \%$ of $\mathrm{N}_{2}$ concentration. This is not just about the cooling capacity but also about compressor work. The compressor power increased after $\mathrm{N}_{2}$ was added, but the rise rates were less than that of the cooling capacity under the current operating conditions. The COP fells at a concentration of $4 \%$.

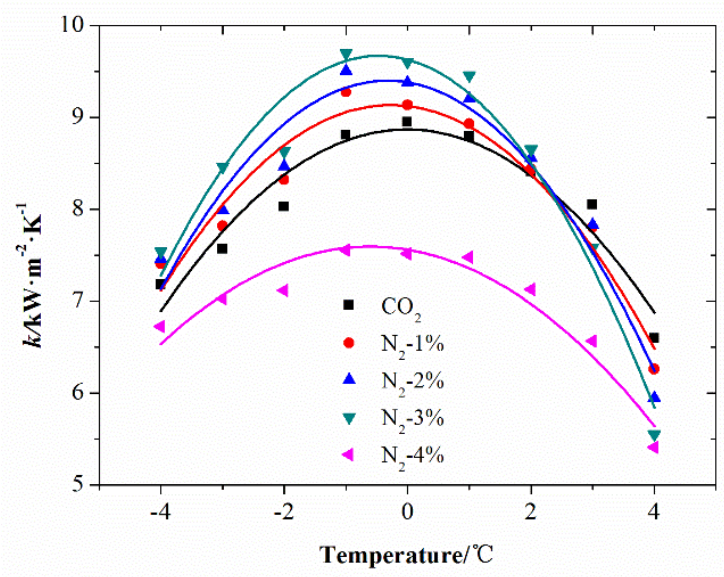

Fig. 8 Effect of $\mathrm{N}_{2}$ on the heat transfer coefficient

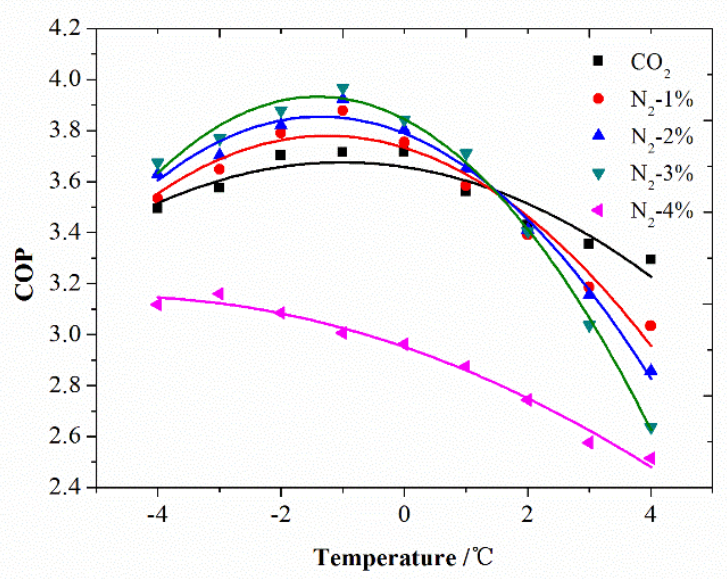

Fig. 9 Effect of $\mathrm{N}_{2}$ on refrigeration system performance

Fig.10 shows the influence of $\mathrm{Ar}$ on the heat transfer coefficient, based on the experimental data. When the inlet temperature is lower, the heat transfer coefficient is higher with the concentration of Ar ranging from $1 \%$ to $3 \%$. At $-1{ }^{\circ} \mathrm{C}$, $k$ increases by $1.35 \%, 1.39 \%$ and $3.78 \%$ when the concentration of $\mathrm{Ar}$ is $1 \%, 2 \%$ and $3 \%$, respectively. The results show that the change extent is lower than the change of evaporator heat transfer performance with $\mathrm{N}_{2}$.

The graph in Fig.11 reports the COP versus the inlet temperature with different addition quantities of Ar. In comparison, $\mathrm{N}_{2}$ and Ar exhibit a similar influence tendency, except that Ar caused smaller rate changes. Ar and $\mathrm{N}_{2}$ have very similar properties, which have action on accelerating the phase change process and improve the evaporator performance as the non-condensable gas at a certain concentration in certain range of inlet temperature. But since the physical parameters of $\mathrm{Ar}$ is closed to $\mathrm{CO}_{2}$ than $\mathrm{N}_{2}$, the impact of addition Ar is less.

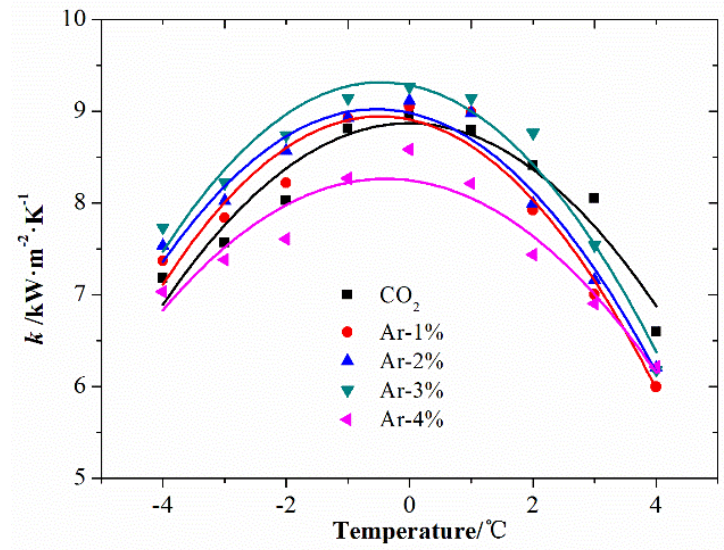

Fig. 10 Effect of Ar on the heat transfer coefficient

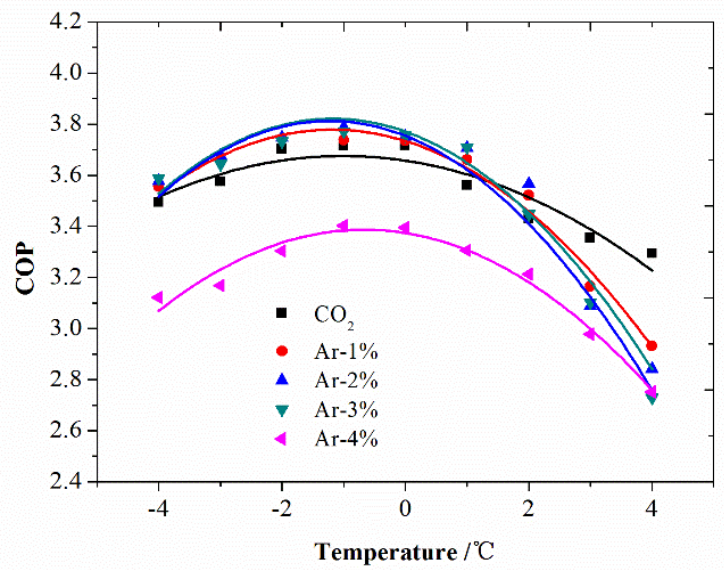

Fig. 11 Effect of Ar on refrigeration system performance 


\section{CONCLUSIONS}

This highlighted the influence of residual non-condensable gases on the heat transfer performance and efficiency of the trans-critical $\mathrm{CO}_{2}$ refrigerating system. The theoretical analysis indicated that the existence of a dissolved gas, randomly residual trapped-vapor (gas) could effectively lower nucleation temperature.

Parameters of the refrigerant properties and the $\mathrm{CO}_{2}$ trans-critical cycle are less affected with a small additive quantity. Nevertheless, phase change from liquid to gas gives more intense influence. The experimental results show that when $\mathrm{N}_{2}$ or $\mathrm{Ar}$ was less than $3 \%$, the evaporator heat transfer performance is improved when the inlet temperature is lower. And the COP increased at lower inlet temperature within 1\%, 2\%, and 3\% of $\mathrm{N}_{2}$ and Ar concentration. On the other hand, the experimental results show that the heat transfer coefficient could be reduced at higher temperature by adding $\mathrm{N}_{2}$ or Ar. The reason is that as the temperature increases, the surface tension decreases and the nuclear boiling process is very easy to occur. Meanwhile, non-condensable gases speed ups the stirring of the swirling boundary layer to improve dryout of $\mathrm{CO}_{2}$. When increasing $\mathrm{N}_{2}$ or Ar concentration to $4 \%$, lower heat transfer coefficients are measured. This is due to the change in thermophysical properties at higher $\mathrm{N}_{2}$ or Ar concentration, in which saturation pressure increase sharply, and the liquid film may be entrained more easily into the vapour core and the dryout inception can be encountered at lower quality.

\section{ACKNOWLEDGEMENTS}

This research was funded by Research project of Tianjin Municipal Education Commission, grant number 2018KJ162.

\section{NOMENCLATURE}

$y_{b} \quad$ the height of the vapor bubble formed on the heated wall (m)

$T_{b} \quad$ the vapor temperature in the bubble (K)

$h_{f g} \quad$ the latent heat of vaporization $(\mathrm{J} / \mathrm{kg})$

$J_{h e t} \quad$ the heterogeneous nucleation density $\left(1 / \mathrm{s} \cdot \mathrm{m}^{3}\right)$

$N_{0} \quad$ molecule number per unit volume (-)

$T_{\mathrm{nl}} \quad$ nucleation temperature in liquid (K)

$r_{c} \quad$ critical bubble size $(\mathrm{m})$

$P_{b} \quad$ the pressures in the vapor bubble (pa)

$P_{l} \quad$ the pressures of liquid phase (pa)

$C_{g} \quad$ the solubility of the dissolved gas in the liquid (-)

$H \quad$ the Henry's law constant for each gas (pa)

$P_{1} \quad$ the equilibrium pressure for the states $\mathrm{T}_{1}$ (pa)

$P_{2} \quad$ the equilibrium pressure for the states $T_{2}(\mathrm{pa})$

$P_{v b} \quad$ the partial pressure of vapor phases (pa)

$P_{g b} \quad$ the partial pressure of gas phases (pa)

$T_{s} \quad$ saturated temperature (K)

$Q \quad$ the heat flow rate exchanged in the tube $(\mathrm{K})$

$T_{\text {wat, in }} \quad$ the chilled water temperatures at inlet (K)

$T_{\text {wat,out }}$ the chilled water temperatures at outlet (K)

A the heat transfer surface area $\left(\mathrm{m}^{2}\right)$

\section{Greek Symbols}

\section{$\rho_{v} \quad$ the density of vapor phase $\left(\mathrm{kg} / \mathrm{m}^{3}\right)$}

$\psi \quad$ the surface available for heterogeneous nucleation per unit bulk volume of the liquid phase (-)

$\omega$ the geometric correction factor for the minimum work required to form a critical nucleus (-)

$\sigma \quad$ the surface tension of liquid $(\mathrm{N} / \mathrm{m})$

$\begin{array}{ll}\text { Subscripts } & \\ \text { het } & \text { heterogeneous nucleation } \\ b & \text { bubble } \\ v & \text { vapor } \\ l & \text { liquid }\end{array}$

$\begin{array}{ll}g & \text { gas } \\ m & \text { mean value } \\ s & \text { saturation }\end{array}$

\section{REFERENCES}

Mastrowski, M., Smolka, J., Hafner A., Haida, M., Palacz M., Banasiak, K., 2019, "Experimental study of the heat transfer problem in expansion devices in $\mathrm{CO}_{2}$ refrigeration systems," Energy. 173, 586-597. https://doi.org/10.1016/j.energy.2019.02.097

Andersen, S.O., Sherman, N.J., Carvalho, S., Gonzalez, M., 2018, “The global search and commercialization of alternatives and substitutes for ozone-depleting substances," Comptes Rendus Geoscience. 350(7), 410424. https://doi.org/10.1016/j.crte.2018.07.010

Abasa, N., Kalairb, A.R., Khanb, N., Haiderc, A., Saleemd, Z., Saleem, M.S., 2018, "Natural and synthetic refrigerants, global warming: A review," Renewable and Sustainable Energy Reviews. 90, 557-569. https://doi.org/10.1016/j.rser.2018.03.099

Lorentzen, G., Petterson, J., 1993, “A new efficient and environmentally benign system for car air-conditioning," International Journal of Refrigeration. 16(1), 4-12. https://doi.org/10.1016/01407007(93)90014-Y

Karampour, M., Sawalha, S., 2018, "State-of-the-art integrated $\mathrm{CO}_{2}$ refrigeration system for supermarkets: A comparative analysis," International Journal of Refrigeration, 86, 239-257. https://doi.org/10.1016/j.ijrefrig.2017.11.006

Hazarika, M.M., Ramgopal, M., Bhattacharyya, S., 2018, "Studies on a transcritical R744 based summer air-conditioning unit: Impact of refrigerant charge on system performance," International Journal of Refrigeration. 89, 22-39. https://doi.org/10.1016/j.ijrefrig.2018.03.007

Ju, F., Fan, X., Chen, Y., Wang, T., Tang, X., Kuang, A., Ma, S., 2018, "Experimental investigation on a heat pump water heater using R744/R290 mixture for domestic hot water," International Journal of Thermal Sciences. 132, 1-13. https://doi.org/10.1016/j.ijthermalsci.2018.05.043

Dai, B., Liu, S., Li, H., Sun, Z., Song, M., Yang, Q., Ma, Y., 2018, "Energetic performance of transcritical $\mathrm{CO}_{2}$ refrigeration cycles with mechanical subcooling using zeotropic mixture as refrigerant," Energy. 150, 205-221. https://doi.org/10.1016/j.energy.2018.02.111

Cao, X., Chu, Q., Song, X., Li, Y., Bian, J., 2019, "Flow characteristics of wet natural gas in different throttling devices," Frontiers in Heat and Mass Transfer. 13, 1-9. https://doi.org/10.5098/hmt.13.2

Wang, Z., Han, F., Sundén, B., 2018, "Parametric evaluation and performance comparison of a modified $\mathrm{CO}_{2}$ transcritical refrigeration cycle in air-conditioning applications," Chemical Engineering Research and Design.131,617-625. https://doi.org/10.1016/j.cherd.2017.08.003

Yu, B., Wang, Da., Liu, C., Jiang, F., Shi, J., Chen, J., 2018, "Performance improvements evaluation of an automobile air conditioning system using $\mathrm{CO}_{2}$-propane mixture as a refrigerant," International Journal of Refrigeration. 88, 172-181. https://doi.org/10.1016/j.ijrefrig.2017.12.016

Nawaz, K., Shen, B., Elatar, A., Baxter, V., Abdelaziz, O., 2018, "Performance optimization of $\mathrm{CO}_{2}$ heat pump water heater," International Journal of Refrigeration. 85, 213-228. https://doi.org/10.1016/j.ijrefrig.2017.09.027

Wang, Z., Wang, F., Ma, Z., Lin, W., Ren, H., 2019, “Investigation on the feasibility and performance of transcritical $\mathrm{CO}_{2}$ heat pump integrated with thermal energy storage for space heating,”. Renewable Energy. 134, 496-508. https://doi.org/10.1016/j.renene.2018.11.035 
Tian, H., Ma, Y.T., Li, M.X., Guan, H.Q., Liu, Z.Y., 2011, “Influence of a non-condensable gas on the performance of a piston expander for use in carbon dioxide trans-critical heat pumps," Applied Thermal Engineering. 31(11-12) 1943-1949. https://doi.org/10.1016/j.applthermaleng.2011.02.041

Li, X., 2013, "Research on the Influence of additive on expansion process and system performance in $\mathrm{CO}_{2}$ Trans-critical heat pump," Tianjin University, Tianjin.

Wu, X., Chu, F., Zhu, Y., Li, Q., 2018, "Vapor free convection film condensation heat transfer in the presence of non-condensable gases with smaller molecular weights than the vapor," Applied Thermal Engineering. 130, 1611-1618. https://doi.org/10.1016/j.applthermaleng.2017.11.109

Yuan, H., Tan, S., Du, W., Ding, S., Guo, C., 2018, "Heterogeneous bubble nucleation model on heated surface based on free energy analysis," International Journal of Heat and Mass Transfer. 122, 1198-1209. https://doi.org/10.1016/j.ijheatmasstransfer.2018.02.062

Pradhan, S., Qader, R.J., Sedai, B.R., Bikkinaa, P.K., 2019, "Influence of wettability on pressure-driven bubble nucleation: A potential method for dissolved gas separation," Separation and Purification Technology. 217, 31-39. https://doi.org/10.1016/j.seppur.2019.02.005

Hong, S., Jiang, S., Hu, Y., Dang, C., Wang, S., 2019, “Visualization investigation of the effects of nanocavity structure on pool boiling enhancement," International Journal of Heat and Mass Transfer. 136,235-245. https://doi.org/10.1016/j.ijheatmasstransfer.2019.03.001

Lu, J.F., Peng, X.F., 2007, "Dynamical evolution of heterogeneous nucleation on surfaces with ideal cavities," Heat and Mass Transfer. 43(7),659-667. https://doi.org/10.1007/s00231-006-0147-1

Corty, C., Foust, A.S., 1955, "Surface variables in nucleate boiling," Chemical Engineering Progress, Symposium Series. 51, 1-12.

Bankoff, S.G., 1958, "Entrapment of gas in the spreading of a liquid over a rough surface,” AIChE Journal. 4(1), 24-26. https://doi.org/10.1002/aic.690040105

Kandlikar, S.G., 2013, “Controlling bubble motion over heated surface through evaporation momentum force to enhance pool boiling heat transfer," Applied Physics Letters. 102(5), 051611. https://doi.org/10.1063/1.4791682

Wang, H., Guo, Z., 2019, “Physical heat transfer," Frontiers in Heat and Mass Transfer. 13,1-12. https://doi.org/10.5098/hmt.13.20
Yuan, H., Tan, S., Feng, L., Liu, X., 2016, “Heterogeneous bubble nucleation on heated surface from insoluble gas," International Journal of Heat and Mass Transfer. 101, 1185-1192. https://doi.org/10.1016/j.ijheatmasstransfer.2016.05.138

Thiagarajan, S.J., Yang, R., King, C., Narumanchi, S., 2015, “Bubble dynamics and nucleate pool boiling heat transfer on microporous copper surfaces," International Journal of Heat and Mass Transfer. 89,12971315. https://doi.org/10.1016/j.ijheatmasstransfer.2015.06.013

Mu, Y.T., Chen, L., He, Y.L., Kang, Q.J., Tao, W.Q., 2017, “Nucleate boiling performance evaluation of cavities at mesoscale level," International Journal of Heat and Mass Transfer. 106, 708-719. https://doi.org/10.1016/j.ijheatmasstransfer.2016.09.058

Tyrrell, J.W.G., Attard, P., 2001, "Images of nanobubbles on hydrophobic surfaces and their interactions,” Physical Review Letters. 87,176104. https://doi.org/10.1103/PhysRevLett.87.176104

Yang, S., Dammer, S.M., Bremond, N., Zandvliet, H.J.W., Kooij, E.S., Lohse, D., 2007, "Characterization of nanobubbles on hydrophobic surfaces in water,” Langmuir. 23(13), $7072-7077$. https://doi.org/10.1021/la070004i

Qi, Y., Klausner, J.F., 2006, “Comparison of nucleation site density for pool boiling and gas nucleation,” Journal of Heat Transfer, 128(1),1320. https://doi.org/10.1115/1.2130399

Nam, Y., Ju, Y.S., 2008, "Bubble nucleation on hydrophobic islands provides evidence to anomalously high contact angles of nanobubbles," Applied Physics Letters, 93,103115. https://doi.org/10.1063/1.2981572

Knapp, R.T., Daily, J.W., and Hammitt, F.G., 1970,“Cavitation,” Mc Graw Hill, New York, USA.

Hsu, Y.Y., 1962, "On the size range of active nucleation cavities on a heating surface," ASME Journal of Heat Transfer. 84, 207-216. https://doi.org/10.1115/1.3684339

Li, J., Cheng, P., 2004, "Bubble cavitation in a microchannel," International Journal of Heat and Mass Transfer. 47(12-13), 2689-2698. https://doi.org/10.1016/j.ijheatmasstransfer.2003.11.020

He, J., Liu, J., Xu, X., 2017, “Analysis and experimental study of the heterogeneous nucleation process in the boiling of mixed refrigerants," International Journal of Heat and Mass Transfer. 105, 1149-1160. https://doi.org/10.1016/j.ijheatmasstransfer.2016.09.096 